\title{
Effect of Oral Methyl Prednisolone on Different Radiological Patterns of Hypersensitivity Pneumonitis
}

\author{
Fatma Ahmed Tony' \\ Youssef Mohamed Amin \\ Soliman ${ }^{2}$ \\ Hoda A Salem ${ }^{3}$ \\ 'Clinical Pharmacy Department, Faculty of \\ Pharmacy, British University in Egypt \\ (BUE), Cairo, Egypt; ${ }^{2}$ Chest Department, \\ El-Kasr Al-Aini Hospital, Faculty of \\ Medicine, Cairo University, Giza, Egypt; \\ ${ }^{3}$ Pharmacy Practice Department, Faculty \\ of Pharmacy, Tabuk University and Al- \\ Azhar University, Nasr City, Egypt
}

Background: Hypersensitivity pneumonitis (HP) is an immune-mediated disorder that causes inflammation of interstitial lung, bronchioles, and alveoli. Although corticosteroids have been used as first line treatment for HP for many years, it does not provide satisfactory results in all patients. The aim of this study is to compare the effect of oral methylprednisolone on different radiological patterns of HP to identify the most adequate candidates for corticosteroids.

Patients and Methods: Fifty-three patients with confirmed diagnosis of HP were divided into two groups according to their radiological patterns based on high resolution computed tomography (HRCT) findings. The first group included 21 patients with fibrotic HP (fHP), the second group included 32 patients without fibrosis; non-fibrotic HP patients (nfHP). The second group is divided into 3 subgroups: mosaic, attenuation, centrilobular nodules and finally, ground-glass opacities. All patients were administered methylprednisolone by dose $0.5 \mathrm{mg} / \mathrm{kg} /$ day for eight consecutive weeks. HRCT was performed at the beginning of the study. Spirometry, six-minute walk and oximetry were performed periodically to assess the patients' progress.

Results: Upon finalizing the treatment process, a significant improvement was noticed in FEV1 $(p<0.001)$, FVC $(p<0.001)$, six-minute walk test $(p=0.001)$ and oximetry $(p<0.05)$ in nfHP compared to the fHP patients. However, there was a significant improvement in $(p<0.01)$, FVC $(p<0.01)$, oximetry $(p<0.01)$ and six-minute walk test $(p<0.01)$ in fibrotic patients after receiving the treatment. There was no significant difference in the response of FEV1 $(p=0.82), \operatorname{FVC}(p=0.15)$, six-minute walk test $(p=0.36)$ and oximetry $(p=0.27)$ among the subgroups of nfHP patients.

Conclusion: It was accordingly concluded that corticosteroid treatment is more effective in treatment of nfHP than fHP patients but still has effect on fibrotic patients. There is no significant difference in the response to corticosteroids among nfHP patients' subgroups.

Keywords: fibrotic hypersensitivity pneumonitis, non-fibrotic hypersensitivity pneumonitis, corticosteroids, radiological pattern

\section{Introduction}

Hypersensitivity pneumonitis (HP) also known as extrinsic allergic alveolitis, a disease that causes inflammation in the alveoli along with the terminal bronchioles. ${ }^{1}$ It mainly occurs in individuals after breathing in antigenic substances present in the environment. ${ }^{2}$ For genetically predisposed individuals, this reaction occurs due to prolonged and repeated inhalation of various types of
Correspondence: Fatma Ahmed Tony Clinical Pharmacy Department, Faculty of Pharmacy, British University in Egypt (BUE), Cairo, II837, Egypt

Tel +20 1004339333

Email Fatmatony242@gmail.com 
dusts, microorganisms; bacteria such as Thermophilic actinomycete found in moldy hay and straw, Klebsiella oxytoca found in humidifiers, mycobacteria such as Mycobacterium avium complex found in outdoor hot tubs and Mycobacterium immunogenum found in metalworking fluid, ${ }^{3}$ fungi such as Absidia corymbifera found in moldy hay and straw and, Aspergillus fumigatus, Aspergillus Flavus found in moldy barley ${ }^{4}$ and other substances to which patient is sensitized commonly organic dusts of animals (i.e., raising birds) or vegetables, and rarely from chemicals. ${ }^{5}$ Furthermore, workers in specific industries such as mining and painting are more prone to develop HP. The sensitization and evolution of HP is primarily due to exposure to more than one antigen, rather than a single one. ${ }^{6,7}$ Symptoms begin with coughing which most probably develops to be severe and productive, patient may present with flu-like symptoms, malaise, dyspnea and in some cases, fever. In some severe cases the patient may show symptoms of wheezing. Upon physical examination there may be rales and rhonchi. ${ }^{8}$

HP diagnostic criteria was based on antigen exposure, pulmonary functions test, high resolution computed tomography (HRCT) findings, biopsies and broncho alveolar lavage (BAL). ${ }^{8,9}$ The radiologic findings of HP are those of acute pulmonary edema, a HRCT should be performed to assess these patients. ${ }^{10}$ The HRCT scans may display patchy or diffuse bilateral ground-glass opacities, poorly defined small centrilobular nodules and lobular areas with reduced attenuation. ${ }^{11}$ Ground-glass opacities generally indicate diffuse lymphocytic interstitial pneumonitis, where poorly defined centrilobular nodules are caused by cellular bronchiolitis or focal areas. The lobular areas of decreased attenuation and air trapping are due to smallairway obstruction by cellular bronchiolitis. ${ }^{12,13}$

Differential diagnosis of HP is further expanded to exclude drug induced hypersensitivity syndrome which commonly manifests symptoms like dyspnea, cough or pleurisy ${ }^{14}$ or any drug toxicity with similar symptoms but the main aspect of diagnosis of HP is antigen exposures which differ HP from any drug induced toxicity with respiratory symptoms involvement. ${ }^{8}$ Recent studies were performed to identify the biomarkers for HP which lead to considering results towards gene therapy of HP. ${ }^{15}$

Corticosteroids are an effective anti-inflammatory therapy for many chronic inflammatory diseases. ${ }^{16}$ They reduce immune system activity, accordingly, they are often used in treatment of HP. The objective of this study is to investigate the therapeutic effect of corticosteroids on pulmonary functions evolution in both non-fibrotic pneumonitis (nfHP) and fibrotic pneumonitis (fHP) patients, starting with the hypothesis that corticosteroid effects would not be the same in nfHP and fHP patients. So by evaluating the patients' clinical and functional status after finishing the treatment course we will be able to specify which HP patients will gain the best benefit from taking corticosteroids so that other patients will be protected from prescribing unneeded medication with numerous side effects.

\section{Patients and Methods Study Design}

A parallel comparative prospective trial was conducted at Al-Kasr Al-Aini Hospital, Chest department, Giza, Egypt. The patients were identified by coded numbers to ensure the patients' privacy, the patients willingly signed a written informed consent before contributing in the study, the patients were classified based on their radiological pattern, so any bias is eliminated. The study was carried out after approval of the medical ethics committee number N-172-2018, registration in ClinicalTrials.gov NCT04402177. The study was conducted in compliance and accordance to the ethical principles originated in the Declaration of Helsinki Good Clinical Practice.

\section{Patient Selection}

Enrollment eligible patients at baseline were male or female aged between 20 to 75 years. Patients enrolled in the study were already newly diagnosed with HP at the parenchymal lung diseases department in Al-Kasr Al-Aini Hospital, according to the recent studies done by Raghu et $\mathrm{al}^{17}$ the diagnosis was based on a combination of symptoms, which include dyspnea with or without cough which may appear shortly after exposure to antigen, malaise, flu-like symptoms in addition to CT findings, lung function test and having history of exposure to allergen either in work place or at their residence and $\mathrm{BAL}^{18,19}$ and serology tests were carried out in some patients to exclude collagen vascular disease. All patients must be steroid naïve; have not been treated with oral or inhaled corticosteroids for at least two months ${ }^{20}$ to be able to assess the corticosteroid effect. All were with the same causative factors which are birds like pigeons or poultry, to reduce any possible variables other than the effect of the treatment. Patients with respiratory co-morbidities, patients with other types 
of interstitial lung diseases, smokers, patients already taking steroids, patients with history of allergy to corticosteroids, pregnant, or nursing females were excluded from the study.

\section{Sample Size Calculation}

A priori test for sample size calculation was conducted using $\mathrm{G}^{*}$ Power 3.1.9.2 software. A simple assumption of four and three points were chosen for FVC mean difference between the two groups as 4 points and standard deviation, respectively. An alpha $=0.05$, power $(1-\beta)=$ 0.85 and $\mathrm{N} 1 / \mathrm{N} 2$ group ratio $=0.67$ lead to a total number of subjects $=42(\mathrm{~N} 1=17, \mathrm{~N} 2=25)$.

The goal was to include 30 cases in group 1 and 62 cases in group 2 to compensate for subject drop off during the follow-up phase.

\section{Methods}

The study started with 92 patients who had a confirmed diagnosis of HP, of those 92 patients, 53 managed to complete the study. The patients' withdrawal was a result of inefficient follow-up due to the distance and some patients developed other respiratory diseases which did not match the inclusion criteria.

Fifty-three patients were divided into two groups according to their radiological pattern based on HRCT findings. The first group contained 21 patients with fibrosis on HRCT as shown in Figure $1 \mathrm{fHP}$, the second group 32 patients without fibrosis on HRCT (nfHP). Then the second group, nfHP, was divided into three subgroups according to their radiological pattern. Ten patients were showing Mosaic attenuation as shown in Figure 2, eleven patients were showing ground glass opacities as shown in Figure 3 , ten patients showing centrilobular nodules as shown in Figure 4.

All patients underwent the following assessments to evaluate their clinical and functional status:

\section{High Resolution CT of the Chest}

An HRCT of the chest was performed at the start of the study in order to allow the segmentation of groups accordingly. This technique obtains images with superb lung detail, which are ideal for the evaluation of diffuse interstitial lung diseases. It was performed to assess the patient's radiological pattern.

The first group showed fibrosis on the HCRT which was defined as the presence of honeycomb, traction bronchiectasis, extensive reticulation, or a combination of these findings. ${ }^{21}$ The second group were patients with no signs of fibrosis (nfHP); nfHP patients may present with more than one pattern simultaneously, but they were classified according to the dominant pattern which appeared on the HRCT. Mosaic attenuation represents coexisting pneumonitis-affected lobules interspersed with regular or slightly decreased attenuation lobules which is due to bronchiolar obstruction. ${ }^{17}$ Ground glass opacities; a radiological term that clearly suggests a region of hazy increased lung opacity that can still be found through vessels and bronchial structures. ${ }^{22}$ Centrilobular nodules; may become evident at the center of the secondary pulmonary lobe when excessive soft tissue is present in or around the bronchioles. ${ }^{8}$

\section{Spirometry}

Pulmonary function tests were measured by an electronic spirometer (Model-Schiller AG, CH6304). The ventilator function test was carried out in sitting position. Patients had to take deep breath, hold their breath for a couple of seconds, and then exhale as hard as possible into the breathing device. On an automated pulmonary function examination, lung volumes were performed in at least three suitable forced expiratory maneuvers. Forced vital capacity (FVC) and forced expiratory volume in 1 second (FEV1) were recorded. Patients were asked to stop smoking one hour prior to the spirometry, not to wear very tight clothes which may restrict optimum breathing and to avoid heavy meals which may limit breathing capacity.

\section{Six-Minute Walk Test}

Patients were asked to walk for six minutes on a rough flat surface, the entire walking distance, and the area covered were later measured.

The purpose of this test is to spend six minutes walking as far as possible. The patient was asked to walk between the marks, as many times as he could in six minutes, along the corridor. The patients were notified when each minute passed, and then the patients were asked to stop where they were six minutes into the test and place a mark on the distance walked. The patients were seated at the end or if the patient preferred, they were allowed to stand.

\section{Oximetry}

Pulse oximeter (Ana Pulse 100, Ana Wiz Ltd., and UK) was used to measure the amount of oxygen transported through the body. This is a non-invasive tool that connects to the fingertip painlessly. The oximeter records the percentage of oxygen in the blood flowing from the heart and 


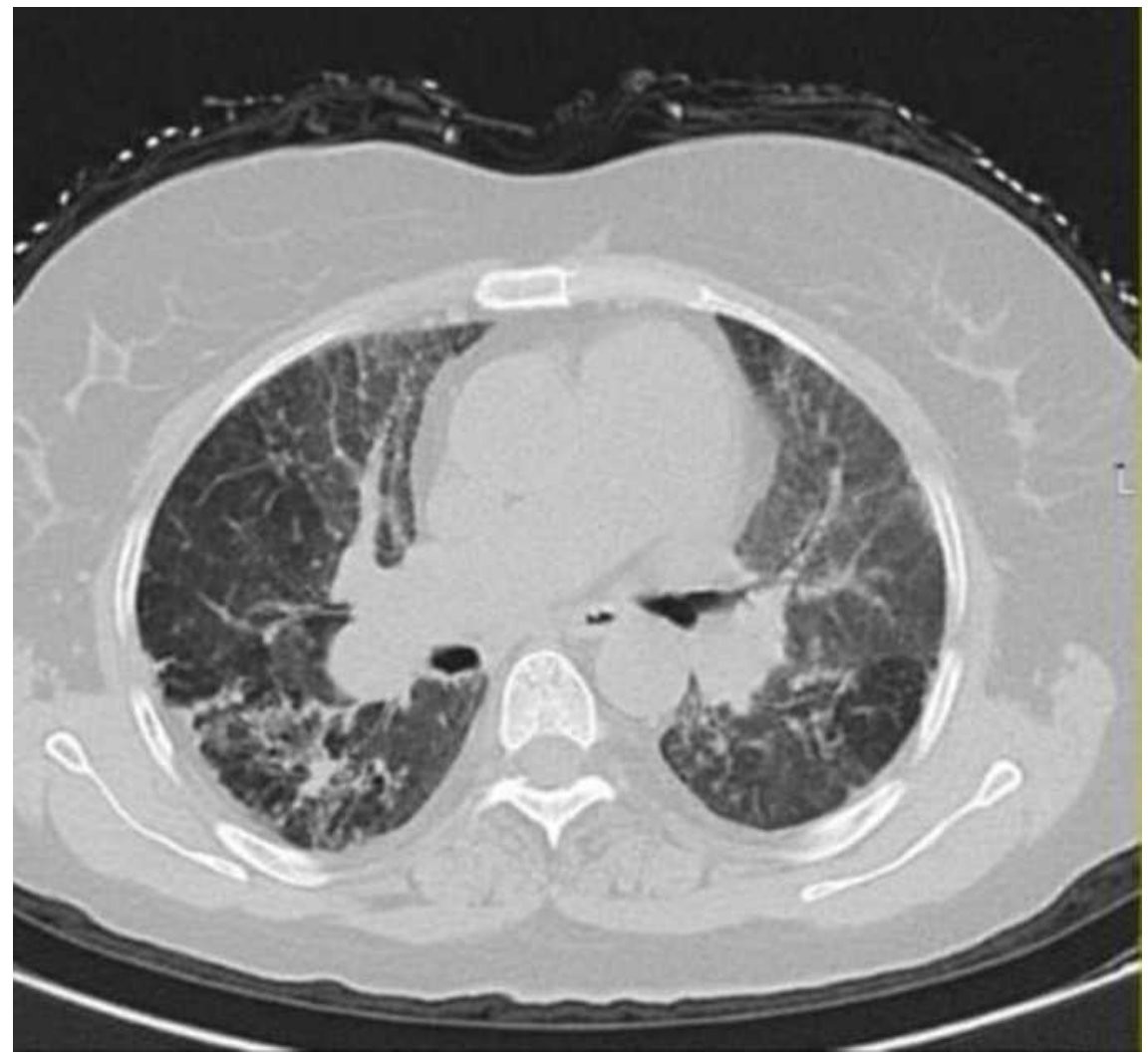

Figure I HRCT of chest for patient with fibrosis.

displays it on its screen. Percentage of oxygen in blood was measured before and after exertion, it was measured before and after performing the six-minute walk test.

\section{Study Outcomes}

The study outcomes were designed to measure the improvement in each patient's clinical and functional status after administering $0.5 \mathrm{mg} / \mathrm{kg} /$ day of methyl prednisolone for eight weeks. The change in the patient's FEV1 was measured at the beginning of the study before taking the medication, every two weeks at follow-up, and at the end of the eight week course. The changes in the patient's FVC was measured at the beginning of the study before taking the medication, every two weeks at follow-up, and at the end of the eight week course. Changes in the patient's oximetry before exertion and after exertion by measuring the percentage of oxygen in the blood was measured before and after the designated treatment period. Changes in the "six-minute walk test," which measures the distance an individual is able to walk over a total of six minutes on a hard, flat surface, was measured before and after eight weeks of administering methyl prednisolone.

\section{Treatment}

Methyl prednisolone (Solupred) ${ }^{\circledR}$ Sanofi Aventis company $0.5 \mathrm{mg} / \mathrm{kg} / \mathrm{day}$ was given to all patients for eight weeks once the patient had been diagnosed with HP. ${ }^{23}$

\section{Statistical Method}

Data were coded and entered using the statistical package for the Social Sciences (SPSS) version 26 (IBM Corp., Armonk, NY, USA). Data was summarized using mean and standard deviation for quantitative variables and frequencies (number of cases) and relative frequencies (percentages) for categorical variables. Comparisons between groups were done using unpaired $t$-test for comparing the improvement of fibrotic and non-fibrotic groups every periodic measurement while non-parametric MannWhitney test was used for comparing the improvement between fibrotic and non-fibrotic groups after the designated treatment period. Analysis of variance (ANOVA) with multiple comparisons post hoc test was used to compare between the nfHP subgroups (mosaic attenuation, centrilobular nodules and GGO's) every periodic measurement while non-parametric Kruskal-Wallis test was used 


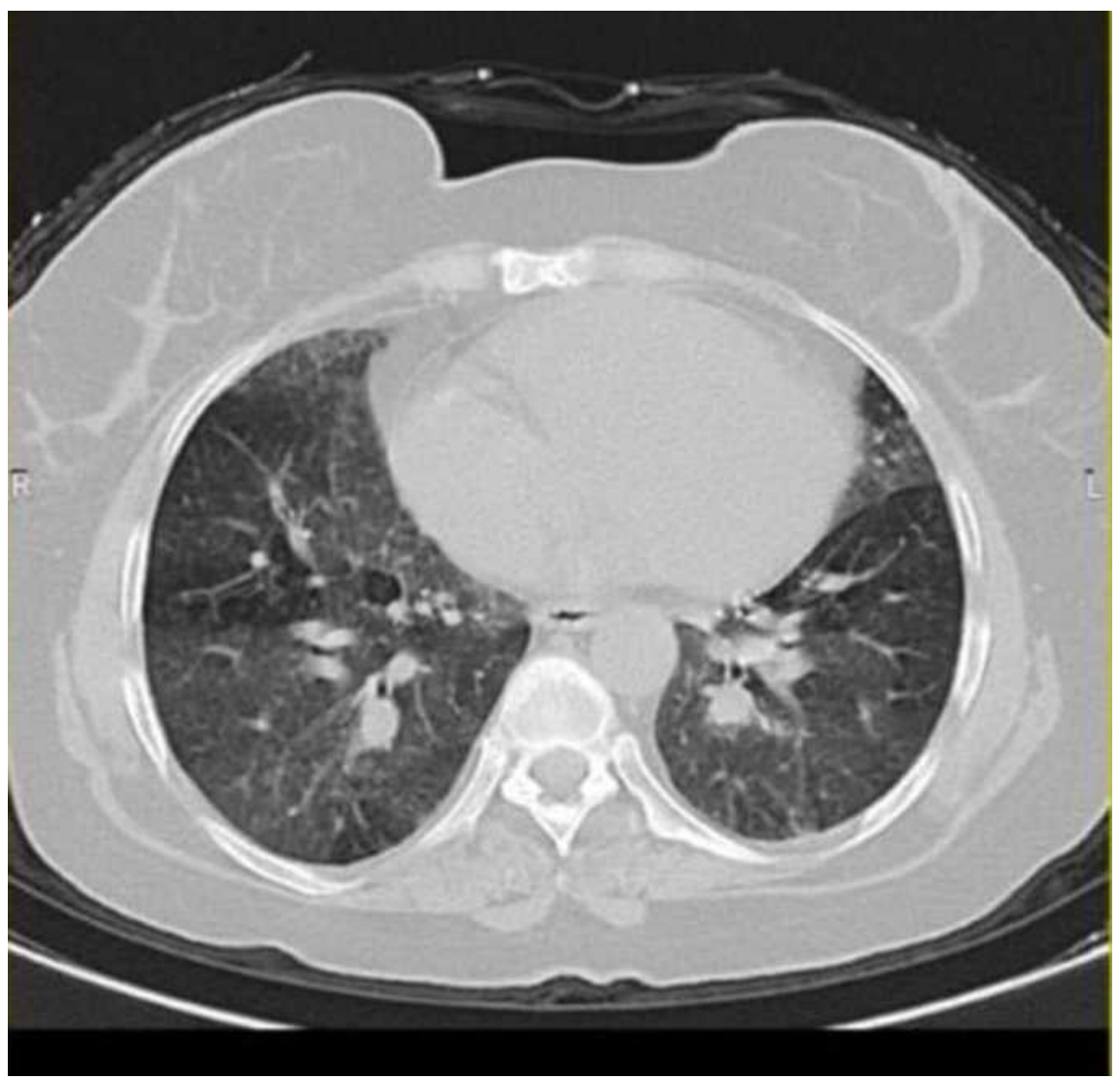

Figure 2 HCRT of chest for showing mosaic attenuation.

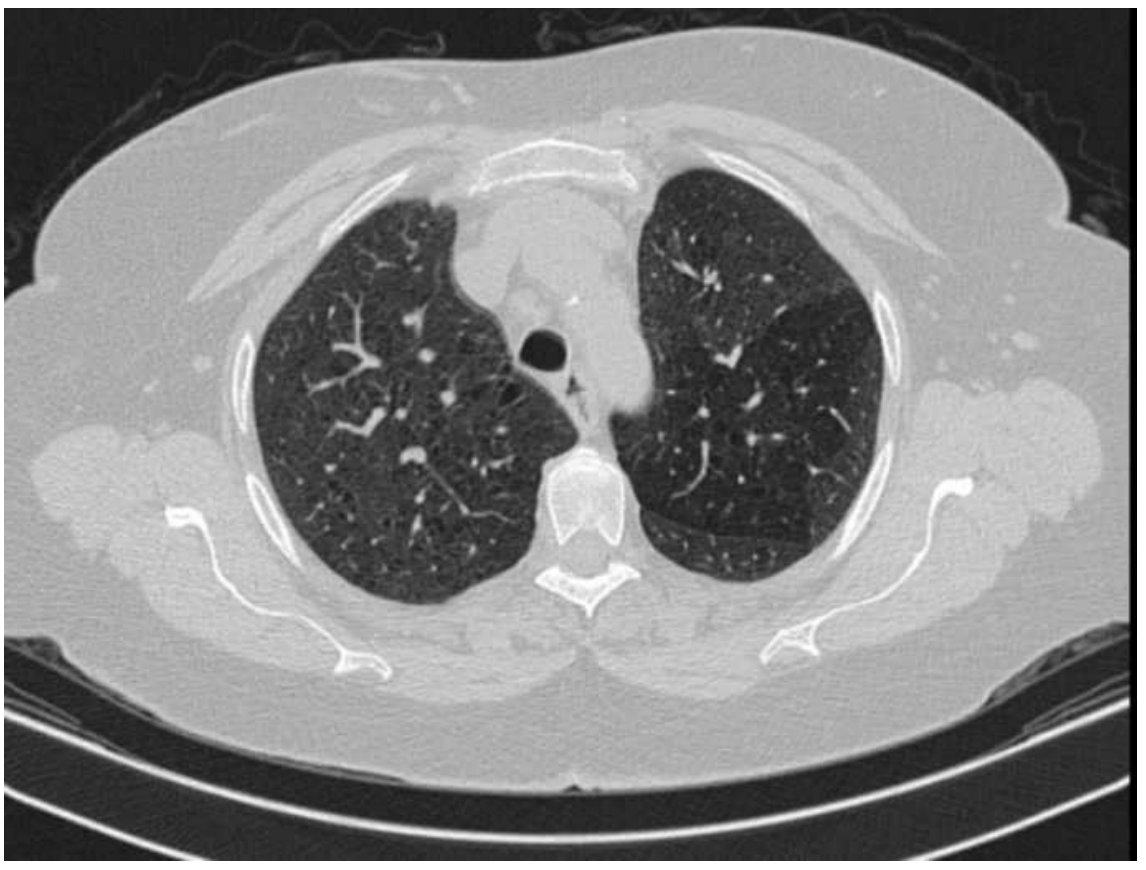

Figure $3 \mathrm{HRCT}$ of chest showing ground glass opacities. 


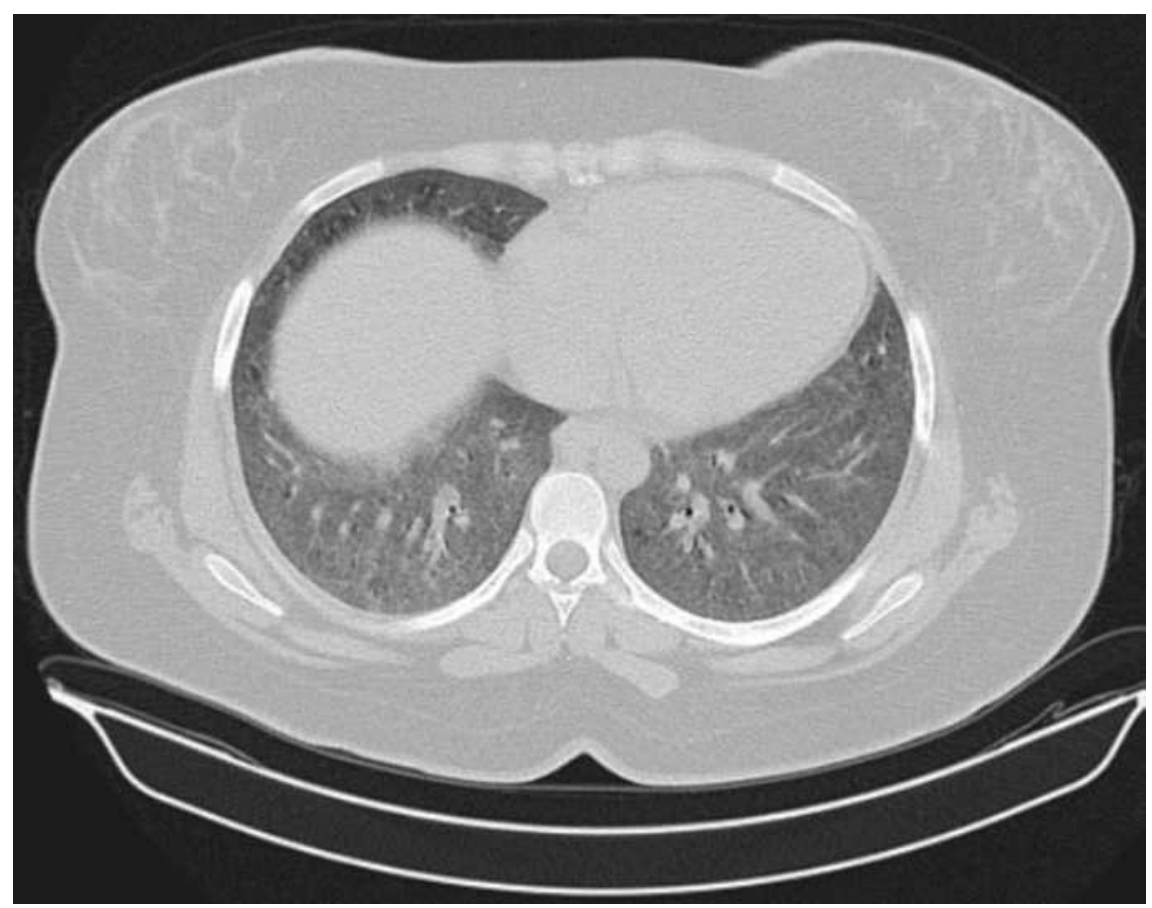

Figure 4 HRCT of chest showing centrilobular nodules.

to compare between the non-fibrotic subgroups after the designated treatment period.

For comparing categorical data, a Chi square test was performed. The exact test was used instead when the expected frequency is less than five. ${ }^{24} \mathrm{P}$ - values less than 0.05 were considered as statistically significant.

\section{Results}

All 53 patients were administered $0.5 \mathrm{mg} / \mathrm{kg} /$ day of methyl prednisolone for eight weeks. The study has a mean age of 49.48 for fibrotic patients and 50.53 for non-fibrotic patients where there is no significant difference in the mean ages of the two groups. The majority were females as shown in Table 1.

The first aspect of the study was to compare the effect of methyl prednisolone between fHP and nfHp by measuring the improvement in lung function tests, six-minute walk test and oximetry. A significant improvement of clinical and functional status was found in the patients with nfHP compared to fHP. There was a significant improvement in $\mathrm{FEV}_{1}(p<0.001)$ (Figure 5A), FVC, $(p<0.001) \quad$ (Figure 5B), oximetry before exertion $(p=0.003) \quad$ (Figure 5C), oximetry after exertion $(p=0.001) \quad$ (Figure 5D) and six-minute walk test $(p=0.001)$ (Figure 5E) in nfHP vs. fHP after taking methylprednisolone for eight weeks, as shown in
Table 2. In other words, methylprednisolone delivers better therapeutic effects in nfHP patients.

The nfHP patients were divided into three groups according to their radiological pattern into mosaic attenuation, centrilobular nodules and ground-glass opacities. After comparing the effect of methylprednisolone among the subgroups of nfHP patients mosaic attenuation vs.ground glass opacities vs. centrilobular nodules and measuring FVC, FEV1, oximetry and sixminute walk test, no significant difference was found in the response of FEV1 $(p=0.82)$ (Figure 6A), FVC

Table I Descriptive Data of the Patients

\begin{tabular}{|c|c|c|c|c|c|}
\hline & \multicolumn{2}{|c|}{ Fibrotic HP } & \multicolumn{2}{|c|}{ Non-Fibrotic HP } & $P$ value \\
\hline Age (years) & \multicolumn{2}{|c|}{$49.48 \pm|3.3|$} & \multicolumn{2}{|c|}{$50.53 \pm 10.21$} & 0.746 \\
\hline Height (m) & \multicolumn{2}{|c|}{$1.65 \pm 0.1$} & \multicolumn{2}{|c|}{$1.67 \pm 0.12$} & 0.728 \\
\hline Weight (Kg) & \multicolumn{2}{|c|}{$95.71 \pm 22.2$} & \multicolumn{2}{|c|}{$93.16 \pm 27.57$} & 0.723 \\
\hline BMI & \multicolumn{2}{|c|}{$35 \pm 7.66$} & \multicolumn{2}{|c|}{$33.11 \pm 6.78$} & 0.348 \\
\hline Sex & Count & $\%$ & Count & $\%$ & $P$ value \\
\hline Male & 8 & $38.10 \%$ & 12 & $37.50 \%$ & 0.965 \\
\hline Female & 13 & $61.90 \%$ & 20 & $62.50 \%$ & \\
\hline
\end{tabular}

Note: Data is presented as mean \pm standard deviation (SD) or as patient numbers (\%).

Abbreviation: BMI, body mass index. 
A

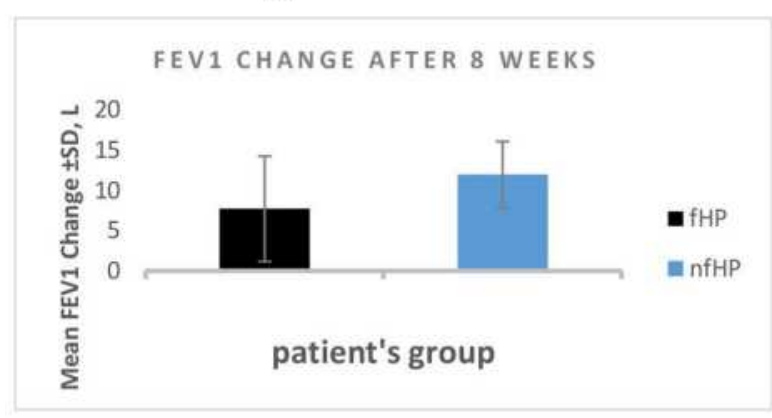

Significant $P$ value $<0.001$

C

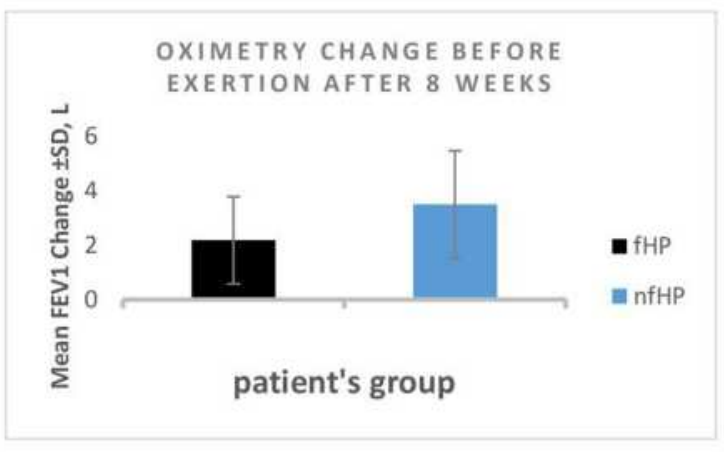

B

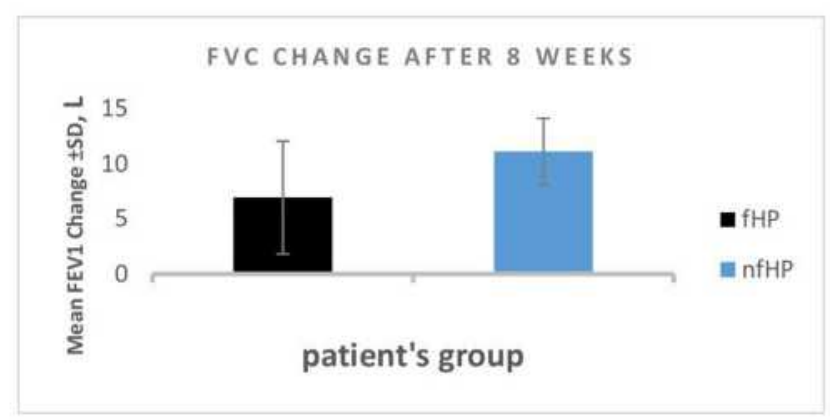

Significant $P$ value $<0.001$

D

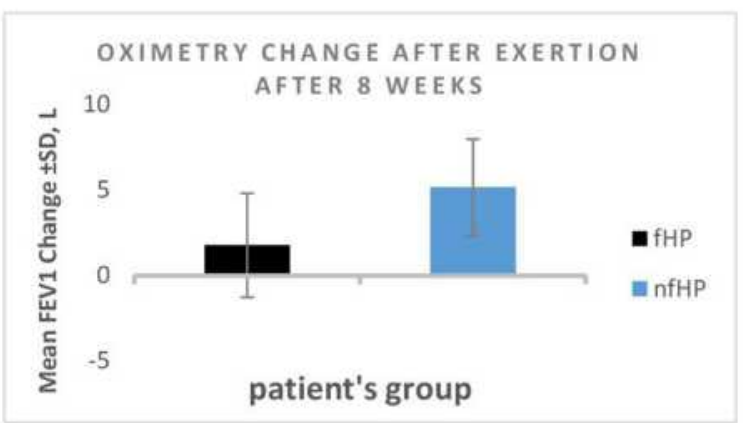

Significant $P$ value $=0.003$

Significant $P$ value $=0.001$

$\mathbf{E}$

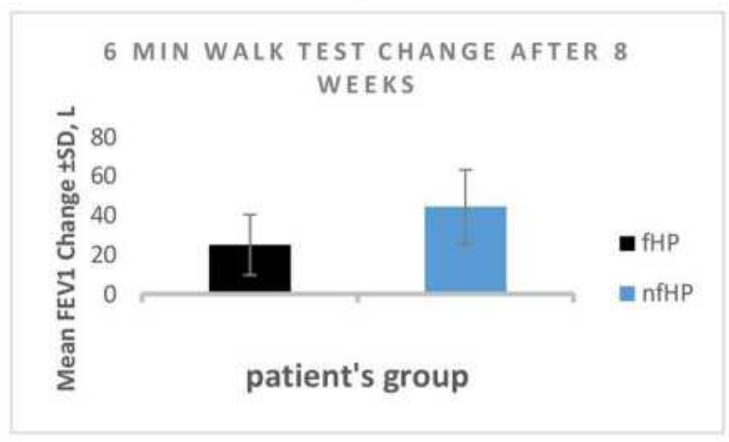

Significant $P$ value $=0.001$

Figure 5 Comparing the effect of methyl prednisolone between fibrotic and non-fibrotic groups after finishing the designated treatment course regarding FEVI (A), FVC (B), oximetry before exertion (C), oximetry after exertion (D), six-minute walk test (E): black (Fhp), blue (nfHP). All p values are significant.

$(p=0.15) \quad$ (Figure 6B), oximetry before exertion $(p=0.27) \quad$ (Figure 6C), oximetry after exertion $(p=0.214)$ (Figure 6D) and six-minute walk test ( $p=0.36$ ) (Figure 6E) after having being taking methylprednisolone for eight weeks of administration of methylprednisolone as shown in Table 2. However, as shown in Table 3 A significant improvement was found of fHP in FEV1 $(p<0.001)$, FVC $(p<0.001)$, oximetry before exertion $(p<0.001)$ oximetry after exertion $(p<$ $0.001)$ and six-minute walk test $(p<0.001)$ after taking the treatment, but not as much as the improvement shown in the nfHP groups.

\section{Discussion}

The study assessed the effect of corticosteroid treatment in both fHP and nfHP patients. Although corticosteroids have 
Table 2 Comparison Between fHP Group and nfHP Group After Taking Methylprednisolone 0.5mg/Kg/Day of for Eight Weeks

\begin{tabular}{|c|c|c|c|c|c|c|c|}
\hline & $\begin{array}{c}\text { Fibrotic } \\
\text { HP }\end{array}$ & $\begin{array}{c}\text { Non-Fibrotic } \\
\text { HP }\end{array}$ & & $\begin{array}{c}\text { Mosaic } \\
\text { Attenuation } \\
\text { nfHP }\end{array}$ & $\begin{array}{l}\text { Centrilobular } \\
\text { Nodules nfHP }\end{array}$ & $\begin{array}{c}\text { Ground Glass } \\
\text { Opacities } \\
\text { nfHP }\end{array}$ & \\
\hline & Mean & Mean & $P$ value & Mean & Mean & Mean & $P$ value \\
\hline FEVI change after eight weeks (L) & $7.72 \pm 6.55$ & $11.97 \pm 4.12$ & $<0.001$ & $11.91 \pm 4.06$ & $12.1 \pm 4.65$ & $11.91 \pm 4.09$ & 0.826 \\
\hline FVC change after eight weeks (L) & $6.95 \pm 5.12$ & $11.12 \pm 3.03$ & $<0.001$ & $9.82 \pm 2.48$ & $12.18 \pm 3.61$ & $11.45 \pm 2.73$ & 0.159 \\
\hline $\begin{array}{l}\text { Oximetry change before exertion } \\
\text { after eight weeks (\%) }\end{array}$ & $2.19 \pm 1.6$ & $3.5 \pm 1.97$ & 0.003 & $4.36 \pm 1.86$ & $3.4 \pm 1.65$ & $2.73 \pm 2.15$ & 0.279 \\
\hline $\begin{array}{l}\text { Oximetry change after exertion } \\
\text { after eight weeks (\%) }\end{array}$ & $1.78 \pm 3.04$ & $5.17 \pm 2.83$ & 0.001 & $6.18 \pm 2.79$ & $5.2 \pm 2.35$ & $3.89 \pm 3.14$ & 0.214 \\
\hline $\begin{array}{l}\text { Six-minute walk change after } \\
\text { eight weeks }(\mathrm{m})\end{array}$ & $25 \pm 15.43$ & $44.33 \pm 19.02$ & 0.001 & $48.18 \pm 17.79$ & $38 \pm 19.32$ & $46.67 \pm 20.46$ & 0.365 \\
\hline
\end{tabular}

Note: Data is presented as mean \pm standard deviation (SD).

Abbreviations: FEVI, forced expiratory volume in I second; FVC, forced vital capacity.

been used as first line treatment for HP for many years, it does not give satisfactory results in all patients.

Patients age ranges from 20-75 years from both sexes were collected. According to the literature the ratio of the disease in Egypt is 10:1 female to male ${ }^{25}$ but in this study the ratio was 2:1 female to male as shown in Table 1. A high percentage of females who initially contributed to the study did not continue till its end since they did not wish to take steroids due to the fear of their side effects. Nevertheless, the study done by Lacasse et alshowed a female to male ratio to be almost $2: 1{ }^{19}$

HRCT is more sensitive than chest radiography. ${ }^{26}$ So it was used in our study to differentiate between fibrotic and non-fibrotic patients.

Lung function tests are very beneficial in the assessment of the initial impact of the disease, to monitor the clinical course under treatment and as a prognostic parameter. $^{19}$ According to the European Respiratory Society (ERS) and American Thoracic Society (ATS) guidelines $^{27}$ three acceptable maneuvers were performed per each measure in spirometry to ensure accurate results. We measured the patient's FEV1 as it is a perfectly suited indicator for airway obstruction. ${ }^{28,29}$ The FVC maneuver depends on rapid maximum inhalation, rapid forced exhalation and continued maximum exhalation. The assessment of FEV1 and FVC was an excellent predictor of the functional state of the lung of the patient. ${ }^{30}$

Pulse oximetry depends mainly on two fundamental points. Firstly, the arterial blood generates pulsatile signals and secondly the fact that oxyhemoglobin and decreased hemoglobin have distinct absorption spectra. ${ }^{31}$ Therefore, it can easily measure the percentage of oxygen in blood by a non- invasive way. The six-minute walk test is safe and reflects the daily living activities more than other tests ${ }^{32,33}$ Patients were permitted to walk on a flat surface without bearing any weight for six minutes unassisted ${ }^{34,35}$ so by measuring pulse oximetry andthe six-minute walk test the patient's functional status can be accurately assessed.

By comparing the effect of methylprednisolone in both nfHP and fHP and measuring FVC, FEV1, oximetry and the six-minute walk test a significant improvement of clinical and functional status of the patients with nfHP was noticed when compared to fHP. There was a significant improvement in FEV1 $(p<0.001)$, FVC $(p<0.001)$, oximetry before exertion $(p=0.003)$, oximetry after exertion $(p=0.001)$ and six-minute walk test ( $p=0.001)$ in nfHP vs. fHP after been taking methylprednisolone for eight weeks of administration of methylprednisolone as shown in Table 2, and this agrees with a study carried out by De Sadeleer et $\mathrm{al}^{21}$ who did a part of the study to assess the effect of corticosteroids on the reversal of the decline of FVC in both nfHP and fHP patients. He found that in nfHP corticosteroid resulted in a reversal from a monthly $\mathrm{FVC} \%$ decline of $0.35 \%$ to an $\mathrm{FVC} \%$ increase of $0.84 \%(p<0.001)$ compared to the changes observed in fHP (FVC\%: $p=0.96)$.

However, as shown in Table 3 a significant improvement of fHP in FEV1 $(p<0.001)$, FVC $(p<0.001)$, 
A

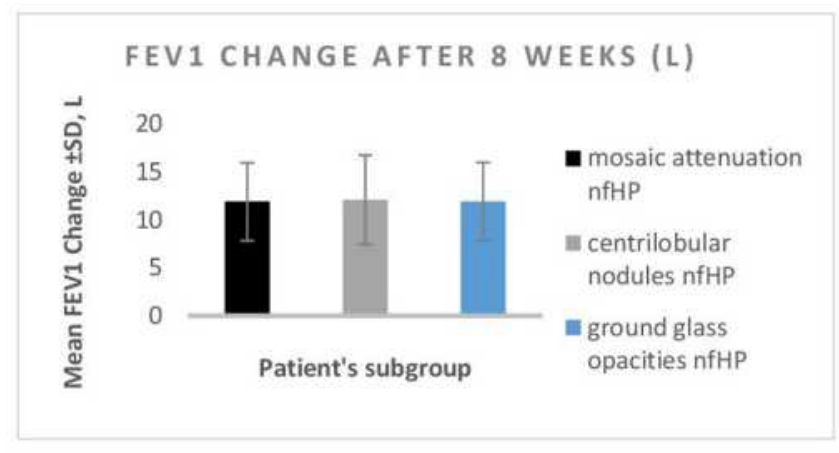

Non-significant $P$ value $=0.82$

C

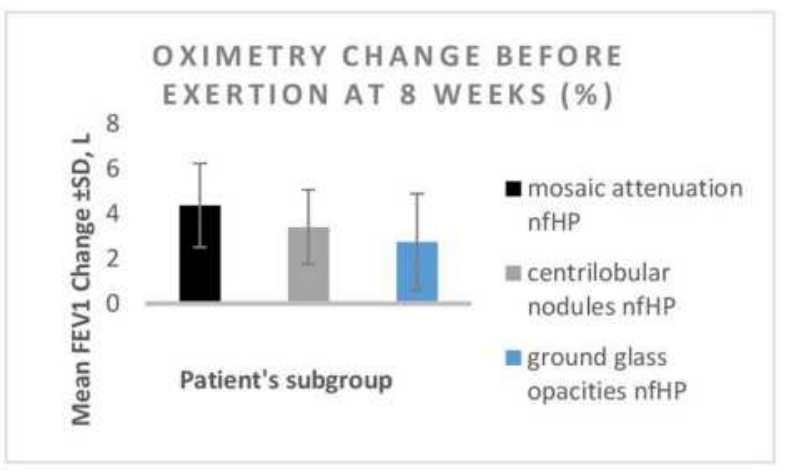

Non-significant $P$ value $=0.27$
B

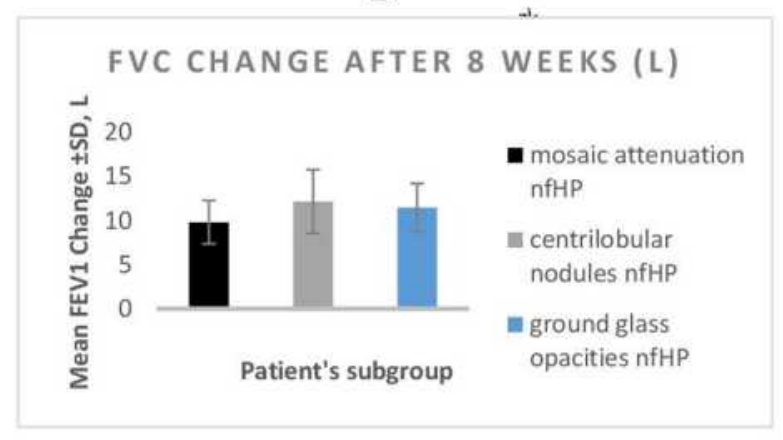

Non-significant $P$ value $=0.15$

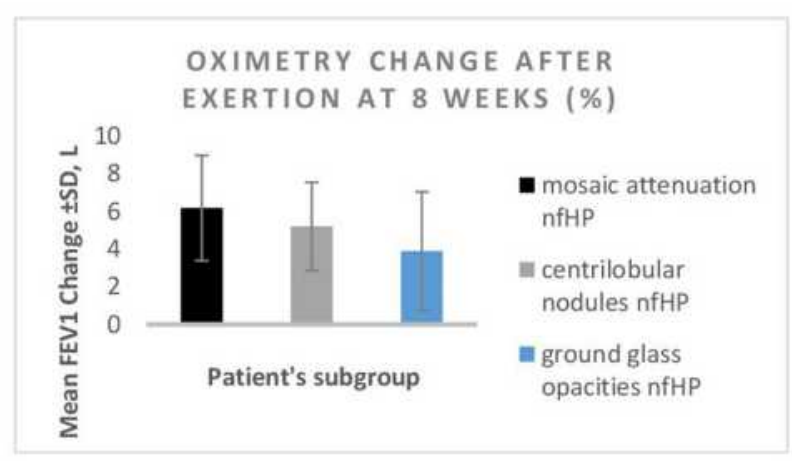

Non-significant $P$ value $=0.21$

E

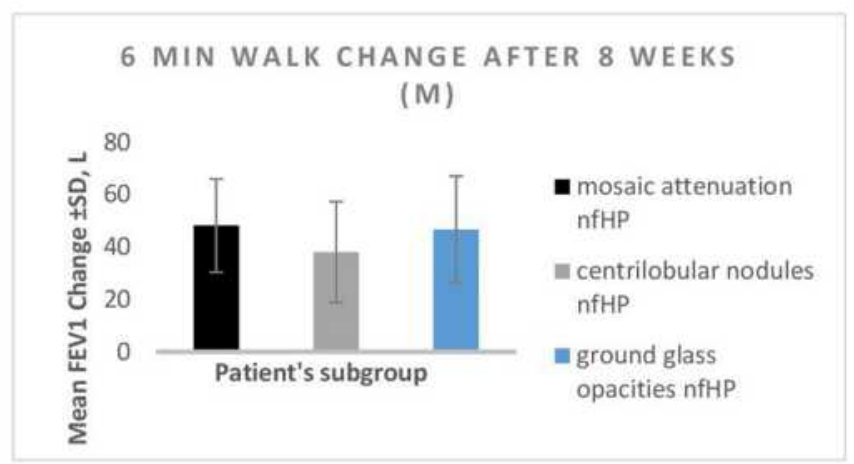

Non-significant $P$ value $=0.36$

Figure 6 Comparing the effect of methyl prednisolone between non-fibrotic subgroups after finishing the designated treatment course regarding FEVI (A), FVC (B), oximetry before exertion (C), oximetry after exertion (D), six-minute walk test (E): black (mosaic attenuation nfHP), gray (centrilobular nodules nfHP), blue (GGO'S nfHP). All $p$ values are non-significant.

oximetry before exertion $(p<0.001)$ oximetry after exertion $(p<0.001)$ and the six-minute walk test $(p<0.001)$ after taking methylprednisolone. This was debatable and discussed by Kouranos et $\mathrm{al}^{36}$ and Varone et $\mathrm{al}^{37}$ who said that fibrotic patients may show improvement after the use of corticosteroids but they suggested antigen avoidance may offer better results. But in a study carried out by Sadeleer et $\mathrm{al}^{38}$ it was found that $\mathrm{FVC} \%$ in fibrotic patients' decline was similar before and after corticosteroid initiation in patients with honeycomb presence $(p=0.78)$. 
Table 3 Fibrotic Patient's Improvement After Taking $0.5 \mathrm{mg} / \mathrm{Kg} /$ Day of Methylprednisolone for Eight Weeks

\begin{tabular}{|c|c|c|}
\hline & \multicolumn{2}{|l|}{ Fibrotic HP } \\
\hline & Mean & $p$ value \\
\hline FEVI at week 0 (L) & $51.17 \pm 6.41$ & \multirow[t]{2}{*}{$<0.001$} \\
\hline FEVI at week $8(\mathrm{~L})$ & $58.89 \pm 10.44$ & \\
\hline FVC at week 0 (L) & $46.07 \pm 6.58$ & \multirow[t]{2}{*}{$<0.001$} \\
\hline FVC at week $8(\mathrm{~L})$ & $53.02 \pm 8.62$ & \\
\hline Oximetry at week 0 before exertion (\%) & $89.67 \pm 3.86$ & \multirow[t]{2}{*}{$<0.001$} \\
\hline Oximetry at week 8 before exertion (\%) & $91.86 \pm 4.04$ & \\
\hline Oximetry at 0 after exertion (\%) & $80.56 \pm 6.20$ & \multirow[t]{2}{*}{$<0.001$} \\
\hline Oximetry at week 8 after exertion (\%) & $81.90 \pm 5.07$ & \\
\hline Six-minute walk test at week $0(\mathrm{~m})$ & $\begin{array}{r}232.22 \\
\pm 49.53\end{array}$ & \multirow[t]{2}{*}{$<0.001$} \\
\hline Six-minute walk test at week $8(\mathrm{~m})$ & $\begin{array}{l}246.67 \\
\pm 57.82\end{array}$ & \\
\hline
\end{tabular}

Note: Data is presented as mean \pm standard deviation (SD).

Abbreviations: FEVI, forced expiratory volume in I second; FVC, forced vital capacity.

However, patients without honeycomb showed a small increase in $\mathrm{FVC} \%$ (4.21\%) after corticosteroid initiation ( $p=0.07$ ). Our rationale for this improvement is that HP is a patchy disease and in the patients with fibrosis there are a non- fibrotic patches. We advocate that increasing the dose or the duration of treatment of corticosteroid may have better results in fHP patients.

Moreover, nfHP patients were divided into three groups according to their radiological pattern into mosaic attenuation, centrilobular nodules and ground-glass opacities. By comparing the effect of methylprednisolone among the subgroups of $\mathrm{nfHP}$ patients mosaic attenuation vs. ground glass opacities vs. centrilobular nodules and measuring FVC, FEV1, oximetry and the six-minute walk test, it was found that there was no significant difference in the response of FEV1 ( $p=0.82)$, FVC ( $p=0.15)$, oximetry before exertion $(p=0.27)$, oximetry after exertion ( $p=0.214$ ), and the six-minute walk test ( $p=0.36$ ), as shown in Table 2 and in agreement with Salisbury et al ${ }^{12}$ and De Sadeleer et al ${ }^{21}$ who found that inall nfHP patients, starting corticosteroid resulted in a reversal from a monthly $\mathrm{FVC} \%$ decline of $0.35 \%$ to an $\mathrm{FVC} \%$ increase of $0.84 \%(p<0.001)$ which support our results that there was no significant difference between the response of different patterns in nfHP patients to corticosteroids.

\section{Conclusion}

In the context of the observed results of this study we can conclude that the corticosteroid treatment gives better therapeutic effects in nfHP patients than in fHP patients, but still have an effect on fHP patients. On the other hand, the study showed that there is no significant difference in the response to corticosteroids among nfHP patients' subgroups

\section{Abbreviations}

HP, hypersensitivity pneumonitis; HRCT, high resolution computed tomography; fHP, fibrotic hypersensitivity pneumonitis; nfHP, non-fibrotic hypersensitivity pneumonitis; BAL, broncho alveolar lavage; FVC, forced vital capacity; FEV1, forced expiratory volume in 1 second; BMI, body mass index; 6MWD, six-minute walk test distance.

\section{Data Sharing Statement}

The data that support the findings of this study are available from the corresponding author upon request.

\section{Disclosure}

The authors reported no conflicts of interest for this work.

\section{References}

1. Morisset J, Johannson KA, Jones KD, et al. Identification of diagnostic criteria for chronic hypersensitivity pneumonitis: an international modified Delphi survey. Am J Respir Crit Care Med. 2018;197 (8):1036-1044. doi:10.1164/rccm.201710-1986OC

2. Riario Sforza GG, Marinou A. Hypersensitivity pneumonitis: a complex lung disease. Clin Mol Allergy. 2017;15:6. doi:10.1186/ s12948-017-0062-7

3. Jacobs RL, Andrews CP, Coalson J. Organic antigen-induced interstitial lung disease: diagnosis and management. Ann Allergy Asthma Immunol. 2002;88(1):30-41. doi:10.1016/S1081-1206(10)63590-9

4. Selman M. Hypersensitivity pneumonitis: a multifaceted deceiving disorder. Clin Chest Med. 2004;25(3):531-547. doi:10.1016/j. ccm.2004.04.001

5. Agache IO, Rogozea L. Management of hypersensivity pneumonitis. Clin Transl Allergy. 2013;3(1):5. doi:10.1186/2045-7022-3-5

6. Vasakova M, Morell F, Walsh S, Leslie K, Raghu G. Hypersensitivity pneumonitis: perspectives in diagnosis and management. Am J Respir Crit Care Med. 2017;196(6):680-689. doi:10.1164/rccm.2016112201PP

7. Wang P, Jones KD, Urisman A, et al. Pathologic findings and prognosis in a large prospective cohort of chronic hypersensitivity pneumonitis. Chest. 2017;152(3):502-509. doi:10.1016/j. chest.2017.02.011

8. Costabel U, Miyazaki Y, Pardo A, et al. Hypersensitivity pneumonitis. Nat Rev Dis Primers. 2020;6(1):65.

9. Pereira CA, Gimenez A, Kuranishi L, Storrer K. Chronic hypersensitivity pneumonitis. J Asthma Allergy. 2016;9:171-181. doi:10.2147/ JAA.S 81540

10. Selman M, Pardo A, King TE. Hypersensitivity pneumonitis insights in diagnosis and pathobiology. Am J Respir Crit Care Med. 2012;186:315-324. doi:10.1164/rccm.201203-0513CI 
11. Salisbury ML, Gross BH, Chughtai A, et al. Development and validation of a radiologic diagnosis model for hypersensitivity pneumonitis. Eur Respir J. 2018;52(2). doi:10.1183/ 13993003.00443-2018.

12. Salisbury ML, Gu T, Murray S, et al. Hypersensitivity pneumonitis: radiologic phenotypes are associated with distinct survival time and pulmonary function trajectory. Chest. 2019;155(4):699-711. doi:10.1016/j.chest.2018.08.1076

13. Salisbury ML, Myers JL, Belloli EA, Kazerooni EA, Martinez FJ, Flaherty KR. Diagnosis and treatment of fibrotic hypersensitivity pneumonia. Where we stand and where we need to go. Am J Respir Crit Care Med. 2017;196(6):690-699. doi:10.1164/rccm.2016081675PP

14. Taweesedt PT, Nordstrom CW, Stoeckel J, Dumic I. Pulmonary manifestations of drug reaction with eosinophilia and systemic symptoms (DRESS) syndrome: a systematic review. Biomed Res Int. 2019;2019:7863815. doi:10.1155/2019/7863815

15. Zhang H, Wang S, Huang T. Identification of chronic hypersensitivity pneumonitis biomarkers with machine learning and differential co-expression analysis. Curr Gene Ther. 2020;20. doi:10.2174/ 1566523220666201208093325 .

16. Jose J, Craig TJ. Hypersensitivity pneumonitis. In: Allergy and Asthma. Cham: Springer; 2016:311-331.

17. Raghu G, Remy-Jardin M, Ryerson CJ, et al. Diagnosis of hypersensitivity pneumonitis in adults. An official ATS/JRS/ALAT clinical practice guideline. American journal of respiratory and critical care medicine. Am J Respir Crit Care Med. 2020;202(3):e36-e69. doi:10.1164/rccm.202005-2032ST

18. Lacasse Y, Selman M, Costabel U, et al. Clinical diagnosis of hypersensitivity pneumonitis. Am J Respir Crit Care Med. 2003;168 (8):952-958. doi:10.1164/rccm.200301-1370C

19. Lacasse Y, Selman M, Costabel U, et al. Classification of hypersensitivity pneumonitis: a hypothesis. Int Arch Allergy Immunol. 2009;149(2):161-166. doi:10.1159/000189200

20. Lee SV de S, Pizzichini MMM, Marques LJ, Ferreira SC, Pizzichini E. Airway inflammation in steroid-naïve asthmatics: characteristics of induced sputum. J Pneumol. 2003;29(4):188-195. doi:10.1590/S0102-35862003000400005

21. De Sadeleer LJ, Hermans F, De Dycker E, et al. Wuyts1,2 effects of corticosteroid treatment and antigen avoidance in a large hypersensitivity pneumonitis cohort: a single-centre cohort study. J Clin Med. 2019;8(1):14. doi:10.3390/jcm8010014

22. Infante M, Lutman RF, Imparato S, et al. Differential diagnosis and management of focal ground-glass opacities. Eur Respir J. 2009;33 (4):821-827. doi:10.1183/09031936.00047908

23. Spagnolo P, Rossi G, Cavazza A, et al. Hypersensitivity pneumonitis: a comprehensive review. J Investig Allergol Clin Immunol. 2015;25 (4):237-250

24. Chan YH. Biostatistics 103: qualitative data -tests of independence. Singapore Med J. 2003;44(10):498-503.
25. Akl Y, Soliman YMA, El-Korashy RI, El-Hennawi HY. Demographic study of hypersensitivity pneumonitis in Egypt: a single center experience. Am J Respir Crit Care Med. 2017;195.

26. Lopes AJ, Mogami R, Capone D, Tessarollo B, de Melo PL, Jansen JM. High-resolution computed tomography in silicosis: correlation with chest radiography and pulmonary function tests. $J$ Bras Pneumol. 2008;34(5):264-272. doi:10.1590/S1806-37132008 000500004

27. Graham BL, Steenbruggen I, Miller MR, et al. Standardization of spirometry 2019 update. An official American thoracic society and European respiratory society technical statement. Am J Respir Crit Care Med. 2019;200(8):70-88. doi:10.1164/rccm.201908-1590ST

28. Enright PL, Studnicka M, Zielinski J. Spirometry to detect and manage chronic obstructive pulmonary disease and asthma in the primary care setting. Eur Respir Mon. 2005;31:1-14

29. Ambastha S, Umesh S, Maheshwari KU, Asokan S. Pulmonary function test using fiber Bragg grating spirometer. J Lightwave Technol. 2016;34(24):5682-5688. doi:10.1109/JLT.2016.2627017

30. Richards JA. Office spirometry-indications and limitations. S Afr Fam Pract. 2006;48(2):48-51. doi:10.1080/20786204.2006. 10873340

31. Jubran A. Advances in respiratory monitoring during mechanical ventilation. Chest. 1999;116(5):1416-1425. doi:10.1378/ chest.116.5.1416

32. Enright PL. The six-minute walk test. Respir Care. 2003;48 (8):783-785

33. Manzar N, Haque AS, Manzar B, Irfan M. The efficacy of spirometry as a screening tool in detection of air flow obstruction. Open Respir Med J. 2010;4(1):71-75. doi:10.2174/1874306401004010071

34. Blanco Pérez JJ, Arnalich Montiel V, Salgado-Barreira Á, et al. The 6-minute walk test as a tool for determining exercise capacity and prognosis in patients with silicosis. Arch Bronconeumol. 2019;55 (2):88-92. doi:10.1016/j.arbres.2018.07.004

35. Nathan SD, Du Bois RM, Albera C, et al. Validation of test performance characteristics and minimal clinically important difference of the 6-minute walk test in patients with idiopathic pulmonary fibrosis. Respir Med. 2015;109(7):914-922. doi:10.1016/j.rmed.2015.04.008

36. Kouranos V, Jacob J, Nicholson A, Renzoni E. Fibrotic hypersensitivity pneumonitis: key issues in diagnosis and management. $J$ Clin Med. 2017;6(6):62. doi:10.3390/jcm6060062

37. Varone F, Iovene B, Sgalla G, et al. Fibrotic hypersensitivity pneumonitis: diagnosis and management. Lung. 2020;198(3):429-440. doi:10.1007/s00408-020-00360-3

38. De Sadeleer LJ, Hermans F, De Dycker E, et al. Impact of BAL lymphocytosis and presence of honeycombing on corticosteroid treatment effect in fibrotic hypersensitivity pneumonitis: a retrospective cohort study. Eur Respir J. 2020;55(4):1901983. doi:10.1183/ 13993003.01983-2019

\section{Publish your work in this journal}

The Journal of Asthma and Allergy is an international, peer-reviewed open-access journal publishing original research, reports, editorials and commentaries on the following topics: Asthma; Pulmonary physiology; Asthma related clinical health; Clinical immunology and the immunological basis of disease; Pharmacological interventions and

Submit your manuscript here: https://www.dovepress.com/journal-of-asthma-and-allergy-journal new therapies. The manuscript management system is completely online and includes a very quick and fair peer-review system, which is all easy to use. Visit http://www.dovepress.com/testimonials.php to read real quotes from published authors. 